\title{
South African Teachers' Attitudes Toward the Inclusion of Learners with Different Abilities in Mainstream Classrooms
}

\author{
Dana K. Donohue* and Juan Bornman \\ Centre for Augmentative and Alternative Communication, University of Pretoria, Pretoria, South \\ Africa
}

This research sought to examine South African teachers' attitudes toward the inclusion of learners with different abilities in their hypothetical mainstream classrooms. Participants were 93 South African teachers who responded to the Teachers' Attitudes and Expectations Scale, a measure developed for this study, regarding four vignettes depicting learners with different types of impairments. Overall, teachers reported that inclusion would benefit learners' social development (mean scores from 2.57 to 3.35 ) more than their intellectual development (mean scores from 2.14 to 2.83). It also was found that teachers overwhelmingly were more confident about including learners with Down syndrome into their hypothetical mainstream classes when compared to the inclusion of learners with other disabilities $F(3,90)=9.59, p<.01$. The results suggest that providing teachers with sufficient resources within the classroom and training that includes hands-on experience with children with disabilities could positively influence their attitudes toward the inclusion of learners with disabilities in their classrooms.

Keywords: Academic achievement; disability; education; inclusion; social skills; South Africa; supports; teachers' attitudes

\section{Introduction}

There is a global movement toward inclusive education (e.g., Salamanca Statement, United Nations Educational, Scientific and Cultural Organization [UNESCO], 1994), where one system of schooling is provided for all a nation's children regardless of whether or not they exhibit disabilities or other barriers to learning. Inclusive policies are suggested to contribute to a more just and equal society (South African Department of Education, 2001), in part, because they

\footnotetext{
*Corresponding author. Email: dana.donohue@gmail.com
} 
expose children to diversity early in life, making diversity a normal rather than abnormal experience. Equality and human rights have been central themes in the lives of South Africans since the end of apartheid in 1994, and educating children of varying races, cultures, genders, and degrees of academic ability together within one classroom may be one way to combat deeply entrenched prejudices that at one time permeated South African society. In this vein, the South African Department of Education published the Education White Paper 6 in 2001, outlining the transformative steps the schooling system would undergo in order to become more inclusive for all South African children. Broadly, inclusive education is viewed as learners with disabilities learning in the same classroom with their same-age typically developing peers using appropriate supports to facilitate their social and intellectual education. Within South Africa specifically, inclusion is viewed within a human rights approach, ensuring that all learners have the same opportunities to a good education that will help them becomes productive citizens (Engelbrecht, 2006).

Rapid political and policy changes do not always translate into what occurs in practice, however, a reality that is evidenced by the lack of progress in implementing inclusive policy in South Africa over the past decade. About $70 \%$ of children of school-going age with disabilities are out of school (Department of Education, 2001) and the vast majority of those attending school are in "special" schools for learners with disabilities, which are separate from mainstream schools for typically developing learners. Although various factors contribute to the current state of inclusive education, teachers' attitudes may be one of the most important facilitators since teachers ultimately have the opportunity to implement or stymie educational policy (Pecek, Cik, \& Lesar, 2008). Teachers' attitudes concerning inclusive education are varied and are influenced by factors at different environmental levels, including learner-level factors, school-level factors, broader cultural- and societal-factors as well as factors related to the teachers themselves. The current 
study seeks to quantitatively determine the attitudes of South African teachers toward the inclusion of learners with different disabilities in mainstream classrooms.

On the teacher-level, for example, research has found that teachers with more education and inclusive training tend to hold more positive attitudes toward learners with disabilities (Avramidis \& Kalyva, 2007; Forlin, Lreman, Sharma, \& Earle, 2009), whereas older teachers tend to hold inclusive attitudes that are more negative (Bornman \& Donohue, 2013). School-level factors such as the resources and provision of supports to teachers also can engender positive or negative attitudes toward the inclusion of learners with disabilities into their classrooms (Avramidis \& Norwich, 2002; Lindqvist \& Nilholm, 2013). The nature and severity of the learner's disability likewise can influence teachers' attitudes (Avramidis, Bayliss, \& Burden, 2000; Avramidis \& Kalyva, 2007; Scruggs \& Mastropieri, 1996), potentially because the degree of learners' impairments can challenge teachers' self-efficacy and self-confidence in overcoming learners' academic barriers.

\section{Variables Affecting Teachers' Attitudes Toward Inclusive Education Policies}

\section{Teacher-Level Factors}

Teachers are expected to be one of the primary drivers behind inclusive policies because they are the gatekeepers for the classroom climate and activities. Various factors have been found to influence teachers' attitudes toward inclusion, including age (Bornman \& Donohue, 2013), education (Forlin et al., 2009), and training (Avramidis \& Norwich, 2002; Scruggs \& Mastropieri, 1996). Current teacher training in South Africa focuses on meeting the needs of a diverse body of learners. Yet, previous training emphasised the distinction between teachers who taught mainstream and special classes, i.e., teachers were trained to teach typically or atypically developing children, but not both. Because of this prior approach of teacher training, many South African educators currently find themselves in a position where they are expected to teach learners with various educational needs and barriers to learning without any relevant experience or training 
(Oswald, 2007). In fact, South African teachers note that their lack of effective preparation is one of the major stressors about the prospect of inclusive education (Engelbrecht, Oswald, Swart, \& Eloff, 2003). In a large study of 2,577 South African primary school teachers, only $36 \%$ of teachers could even describe what inclusive education was (Hay, Smit, \& Paulsen, 2001). Not knowing what to do or how to do it, teachers who lack appropriate inclusive training may quickly become overwhelmed when asked to include a learner with a disability into their mainstream class. Teachers who have been provided with inclusive education training, on the other hand, tend to report more positive attitudes toward inclusion (Avramidis et al., 2000; Subban \& Sharma, 2006). In addition to training, mere exposure to individuals with disabilities has been found to facilitate more positive attitudes regarding educational inclusion (Chhabra, Srivastava, \& Srivastava, 2010). Together, these findings suggest that, when provided with appropriate training, experience, and exposure, teachers can become more self-confident and self-efficacious about their abilities to include learners with disabilities into their classes.

\section{School-Level Factors}

The provision of supports to teachers can contribute to their attitudes concerning inclusive education (Avramidis \& Norwich, 2002), particularly since the academic needs of learners with disabilities can be complex and varied, and beyond what generally is available in a typical South African classroom (Lomofsky \& Lazarus, 2001). School supports can come in various forms and generally should be specialised with consideration toward a learner's particular needs. There are various types of supports, including teacher's aides, smaller class sizes, special equipment, test accommodations for the learner, flexible teaching schedules, and extra non-instructional time to help teachers to adjust their workload. Although supports can foster the inclusion of learners with disabilities into mainstream classrooms, research suggests that they rarely are provided to teachers in South Africa (Nel, Muller, \& Rheeders, 2011). 


\section{Learner-Level Factors}

Teachers' attitudes toward inclusion have been found to be influenced by the nature of a learners' disability (Avramidis \& Kalyva, 2007; Scruggs \& Mastropieri, 1996), potentially because learners with more severe and multiple disabilities have more complex learning needs, require more significant adaptations to the curricula, and one-on-one instructional time. Research has found, for instance, that teachers rated learners with severe intellectual disabilities, autism, and sensory impairments the most challenging to include within a mainstream classroom (Avramidis \& Kalyva). Teachers within South Africa and Lesotho have reported that including learners with intellectual disabilities into their classrooms is particularly difficult (Engelbrecht, Oswald, \& Forlin, 2006; Johnstone \& Chapman, 2009), whereas South African teachers have reported that including children with physical disabilities caused little stress (Eloff, Swart, \& Engelbrecht, 2002).

\section{Teachers' Academic Expectations for Learners with Disabilities}

Children go to school to academically and socially learn in order to eventually become adults who are productive members of society. For learners with disabilities, however, researchers and educators predominantly focus on the psychosocial influences of inclusion and very little attention is paid to the actual academic learning that transpires when learners with disabilities attend mainstream classes (Zoniou-Sideri \& Vlachou, 2006). In a study of inclusion in Lesotho (Johnstone \& Chapman, 2009), teachers were found to teach learners with disabilities in their classes in the few extra minutes they had available in the school day. Moreover, the teachers admitted that their pedagogical approaches were not effective for learners with disabilities, but were fine for the rest of the class (Johnstone \& Chapman), indicating that ensuring that learners with disabilities actually were engaged and participating in the learning process within the classroom was not a priority for some teachers. 
Teachers also have reported that they thought socialization and peer acceptance were the major benefits of inclusion, while few teachers believed that learners with disabilities would profit cognitively or develop in terms of their future career potential (Zoniou-Sideri \& Vlachou, 2006). According to Zoniou-Sideri and Vlachou, "Such emphasis on only the social and moral benefits of inclusion, often influenced by a charitable type of humanism, hinders the translation of this moral commitment into the assertion of rights" (p. 390). In other words, if learners with disabilities are only treated as children who are to be loved and cared for-without giving them academic instruction or setting expectations or goals for their learning-learners with disabilities are never given the opportunity to be empowered. Despite good intentions, the "caring and loving" mind set can become detrimental for learners with disabilities if they are not expected to acquire academic skills in school.

\section{Current Study}

Although several studies have sought to examine how teachers believed including a learner with a disability would influence them, this study sought to examine how teachers thought inclusion would influence the academic and social skills of learners with distinct impairments. Specifically, this study sought to: (1) examine teachers' academic and social expectations for the learners; (2) examine teachers' attitudes concerning the degree of academic adjustments they thought would be necessary to include the learner; and (3) examine the degree to which teachers believed additional supports and resources were necessary to teach learners with different impairments. Teachers were provided with an open-ended question regarding the type of supports that would help them teach each of the learners depicted in the vignettes in this study. Several teacher-level variables such as their age, teaching experience, and experience with learners with disabilities also were examined in relation to the attitudes that they held. 


\section{Method}

Ethical clearance for conducting this research was obtained by the ethics committee of the University of Pretoria. Participants also were provided with consent forms that explained the purpose of the study, that participation was not mandatory, and that they could withdraw from the study at any time without any negative consequences.

\section{Participants}

A total of 110 teachers consented to participate in this study, but data were missing on at least one relevant variable for 17 participants. Little's MCAR test indicated that these data were found to be missing completely at random $\chi^{2}(6)=9.73, p=.14$ and were deleted listwise. The final sample consisted of 93 participants. This convenience sample consisted of teachers who were recruited in two different ways: one group of teachers taught in various special schools across three South African provinces $(n=66)$ and were participating in a larger study concerning the fulfilment of the human rights of children with disabilities in South Africa; the other group were teachers who taught in mainstream or special schools and were enrolled in a university programme to obtain an advanced certificate in educating learners with severe disabilities $(n=27)$. They varied in terms of age (22 - 69 years of age, $M=47.53)$ and teaching experience $(2-40$ years, $M=19.61)$. Most of the sample had experience teaching learners with disabilities $(n=86)$, had training in inclusive education $(n=61)$, and had at least two years of college experience $(M=14.72$ years of total education). The descriptives of this sample can be found in Table 1 .

\section{Measures}

\section{Vignettes}

Four written vignettes were developed for the purpose of this study. Written vignettes were used to control for the potential confounding effects of learners' appearances. These vignettes described learners with disabilities who would be included into the teachers' hypothetical third grade 
Table 1.

Participant descriptives: Range, means, standard deviations, and frequencies $(\mathrm{N}=93)$.

\begin{tabular}{|c|c|c|c|}
\hline Item & Range & Mean & SD \\
\hline Teachers' ages & $22-69$ & 47.53 & 8.99 \\
\hline Years of education & $12-18$ & 14.72 & 1.23 \\
\hline Years teaching & $2-40$ & 19.61 & 9.27 \\
\hline \multirow[t]{2}{*}{ Training in inclusive education? } & Yes & No & \\
\hline & $\mathrm{n}=61$ & $\mathrm{n}=32$ & \\
\hline \multirow[t]{2}{*}{ Taught learner with disability? } & Yes & No & \\
\hline & $\mathrm{n}=86$ & $\mathrm{n}=7$ & \\
\hline \multirow[t]{4}{*}{ Teacher recruited from: } & Special school from & ACE program at & \\
\hline & one of three & University of Pretoria & \\
\hline & provinces & $\mathrm{n}=27$ & \\
\hline & $\mathrm{n}=66$ & & \\
\hline Special schools province & Gauteng & KwaZulu Natal & Limpopo \\
\hline$(\mathrm{n}=66)$ & $\mathrm{n}=41$ & $\mathrm{n}=19$ & $\mathrm{n}=6$ \\
\hline
\end{tabular}

mainstream class and were designed to contrast the different needs and environmental supports that the learners would require. Vignette A described a learner who had congenital blindness but good verbal abilities; Vignette B described a learner with autism whose IQ was average, but who exhibited serious deficits in his social skills; Vignette $\mathrm{C}$ described a learner with spastic quadriplegia who had a mild intellectual impairment and needed to wear diapers to school; and Vignette D described a learner with Down syndrome who had a mild intellectual impairment but had never exhibited challenging behaviours. 


\section{Teachers' Attitudes and Expectations Scale}

A questionnaire was developed to examine teachers' attitudes toward the inclusion of learners with different types of disabilities into their classroom based on items that had been reported in the literature to impact on inclusion. The content validity of this measure was assessed using Lawshe's technique (1975), which provides an indication of the degree to which experts in the field (in this case, teachers) agree that an item on the questionnaire is necessary to measure the topic of interest. Twenty questionnaires were provided to a panel of South African teachers (who did not participate in the main study) and they were asked to rate whether the particular items on the measure were important to ask teachers when trying to gauge teachers' attitudes regarding inclusive education. They responded to the necessity of the items on the measure by checking one of three categories: “essential”, "useful, but not necessary", or "not necessary". Lawshe’s technique (1975) provides a formula for the content validity ratio (CVR), which indicates whether or not the item is essential to include in the measure. The CVR $=(($ number of "essential" responses $-(\mathrm{N} / 2)) /(\mathrm{N} / 2)$. This equation provides CVRs from -1 to +1 . Positive values indicate that the item should be included in the measure. Table 2 illustrates these results.

Following the results of the content validity analysis, two items were removed from the measure: (1) Attending a mainstream class will help this learner find employment in the future (originally Item 5), and (2) How important are incentives for you to help teach this learner? (originally Item 11). The final questionnaire included items about the learner's expected academic progress, social and intellectual development, items about the degree of academic adjustments teachers think would be needed to include the learner in a mainstream class (e.g., curricula adaptations), and provision of school supports to facilitate the process of inclusion. Teachers responded to the Teachers' Attitudes and Expectations Scale using a 5-point Likert scale, with 1 indicating the least, and 5 indicating the most agreement with the statement. The last item on the scale asked teachers how important supports were to teach that particular learner. After rating this 


\section{J. Bornman \& D. K. Donohue}

Table 2.

Content validity for Teachers' Attitudes and Expectations Scale $(\mathrm{N}=20)$.

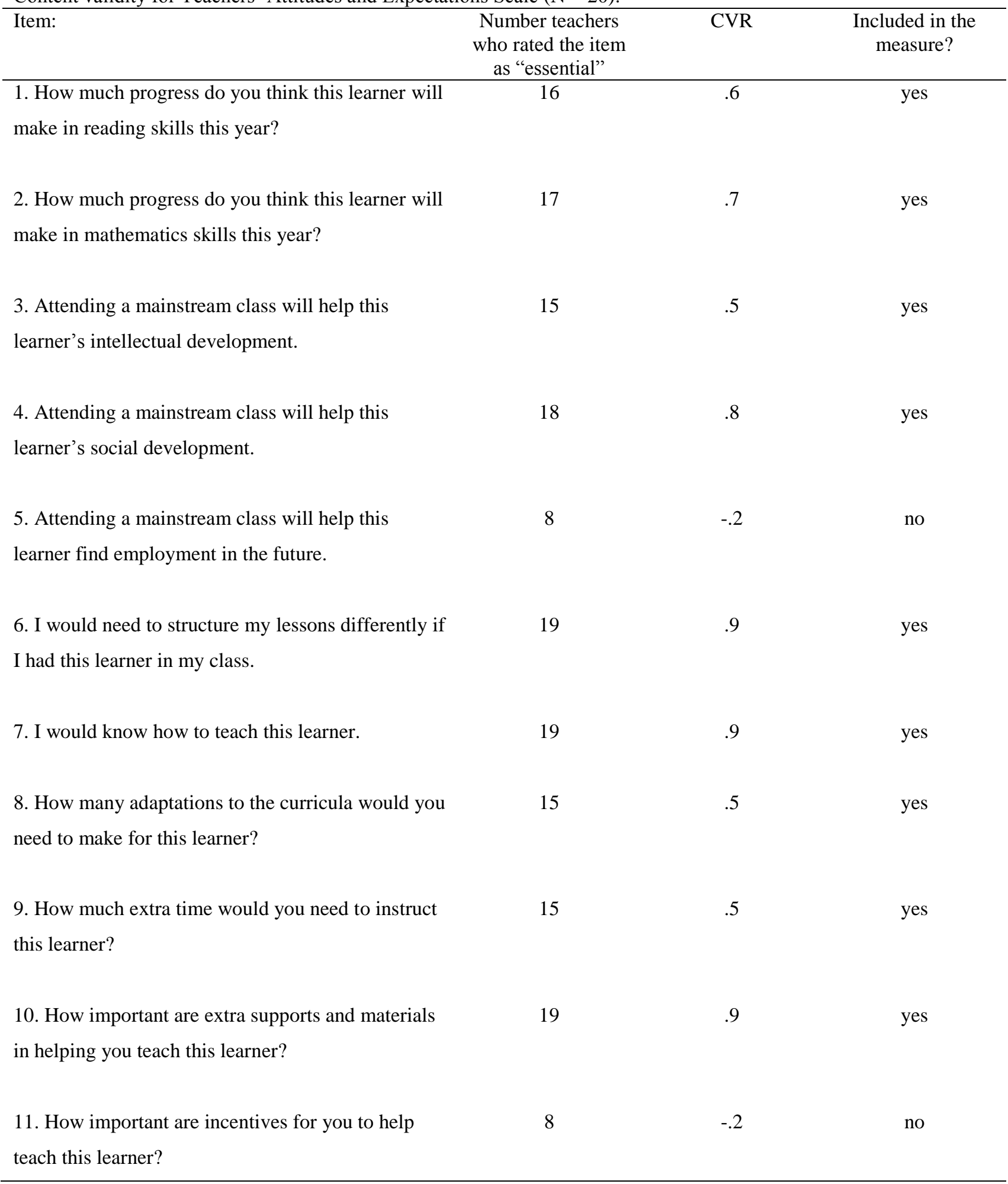

item on the Likert scale, teachers were provided with an open-ended question that asked what types of supports would most facilitate the inclusion of the learner. 


\section{Procedure}

The vignettes were counterbalanced to prevent order effects. After reading each vignette, teachers completed a separate Teachers' Attitudes and Expectations Scale for the learner depicted in the vignette. After completing these measures, the participants completed a biographical survey regarding factors including their age, educational qualifications, and teaching experience.

\section{Data Analysis}

Data screening and analyses were conducted using the Statistical Package for the Social Sciences 20.0 (SPSS). The data first were examined for accuracy of data entry, missing data, and outliers. Missing data were handled using listwise deletion. Repeated measures ANOVAs were run for each item on the Teachers' Attitudes and Expectation Scale to compare and contrast the attitudes teachers held for the learners. Post-hoc t-tests using a Bonferonni correction $(p<.05$ divided by six comparisons yielding a statistical significance level of $p<.008$ ) were used to determine which groups significantly differed from one another. Then, an exploratory factor analysis was run in order to find and compute composite scores. These composite scores were: (1) teachers' overall expectations for the learner, and (2) overall adjustments that would be needed to include the learner in a mainstream class. MANOVA analyses were conducted to determine whether teachers' biographical factors predicted any differences in the two composite measures for the different learners. Frequencies also were run to determine the supports that teachers reported would be essential facilitators for the inclusive education of each learner.

\section{Results}

The results for the Teachers' Attitudes and Expectations Scale are illustrated in Table 3 and are presented both descriptively and comparatively. The superscripts by each mean and standard deviation in Table 3 denote a statistically significant post-hoc comparison between the groups. Item 1 inquired about learners' expected reading progress, with higher means indicating that the learner would make more reading progress over the course of the year. Overall, the results 


\section{J. Bornman \& D. K. Donohue}

suggested that teachers did not expect any of the learners to make significant reading progress. The means revealed that teachers reported that the learner who was blind would make the least reading progress over the course of the year $(\mathrm{M}=2.54, \mathrm{SD}=1.12)$, whereas the learner with Down syndrome would make the most reading progress $(\mathrm{M}=3.02, \mathrm{SD}=.90)$. An overall ANOVA analysis revealed significant differences in the reading expectations between the learners $F(3,90)$ $=5.63, p<.01$. Post-hoc contrasts showed the significant differences between the groups (see Table 1, Item 1 superscripts).

Table 3.

Means, standard deviations, ANOVAs, and contrasts between learners for the Teachers' Attitudes and Expectations Scale $(\mathrm{N}=93)$.

\begin{tabular}{|c|c|c|c|c|c|c|c|}
\hline Item & $\begin{array}{c}\text { Vignette A: } \\
\text { Learner with } \\
\text { Blindness }\end{array}$ & $\begin{array}{c}\text { Vignette B: } \\
\text { Learner with } \\
\text { Autism }\end{array}$ & $\begin{array}{c}\text { Vignette C: } \\
\text { Learner with } \\
\text { Spastic } \\
\text { Quadriplegia }\end{array}$ & $\begin{array}{c}\text { Vignette D: } \\
\text { Learner with } \\
\text { Down } \\
\text { syndrome }\end{array}$ & $\mathrm{F}$ & $\mathrm{df}$ & $\mathrm{p}$ \\
\hline 1. Reading progress & $2.54(1.12)^{\mathrm{ab}}$ & $2.99(.96)^{\mathrm{a}}$ & $2.69(.98)^{\mathrm{c}}$ & $3.02(.90)^{\mathrm{bc}}$ & 5.63 & 3,90 & .00 \\
\hline $\begin{array}{l}\text { 2. Mathematics } \\
\text { progress }\end{array}$ & $3.24(1.02)^{\mathrm{ab}}$ & $3.02(1.00)^{\mathrm{c}}$ & $2.56(.89)^{\mathrm{acd}}$ & $2.89(.91)^{\mathrm{bd}}$ & 11.49 & 3,90 & .00 \\
\hline $\begin{array}{l}\text { 3. Intellectual } \\
\text { development }\end{array}$ & $2.83(1.47)^{\mathrm{a}}$ & $2.46(1.36)^{\mathrm{b}}$ & $2.14(1.25)^{\mathrm{ac}}$ & $2.82(1.31)^{\mathrm{bc}}$ & 14.46 & 3,90 & .00 \\
\hline $\begin{array}{l}\text { 4. Social } \\
\text { development }\end{array}$ & $3.35(1.54)^{\mathrm{ab}}$ & $2.57(1.43)^{\mathrm{ac}}$ & $2.65(1.40)^{\mathrm{bd}}$ & $3.33(1.44)^{\mathrm{cd}}$ & 27.13 & 3,90 & .00 \\
\hline $\begin{array}{l}\text { 5. Structure lessons } \\
\text { differently }\end{array}$ & $4.85(.53)^{\mathrm{ac}}$ & $4.60(.86)^{\mathrm{b}}$ & $4.58(.88)^{\mathrm{a}}$ & $4.27(.96)^{\mathrm{cb}}$ & 10.03 & 3,90 & .00 \\
\hline $\begin{array}{l}\text { 6. Know how to } \\
\text { teach }\end{array}$ & $3.24(1.38)^{\mathrm{a}}$ & $3.42(1.42)^{\mathrm{b}}$ & $3.59(1.41)^{\mathrm{c}}$ & $4.02(1.15)^{\mathrm{abc}}$ & 9.59 & 3,90 & .00 \\
\hline $\begin{array}{l}\text { 7. Curricula } \\
\text { adaptations }\end{array}$ & $3.84(.95)$ & $3.72(.98)$ & $3.91(.89)^{\mathrm{a}}$ & $3.53(1.07)^{\mathrm{a}}$ & 4.78 & 3,90 & .00 \\
\hline $\begin{array}{l}\text { 8. Extra time to } \\
\text { teach }\end{array}$ & $3.64(1.08)^{\mathrm{a}}$ & $3.64(1.29)^{\mathrm{b}}$ & $3.87(1.24)^{\mathrm{c}}$ & $3.30(1.21)^{\mathrm{abc}}$ & 9.74 & 3,90 & .00 \\
\hline $\begin{array}{l}\text { 9. Extra resources to } \\
\text { teach }\end{array}$ & $4.83(.46)^{\mathrm{ab}}$ & $4.49(.95)^{\mathrm{ac}}$ & $4.78(.59)^{\mathrm{cd}}$ & $4.27(1.06)^{\mathrm{bd}}$ & 10.37 & 3,90 & .00 \\
\hline
\end{tabular}


Low mean scores also can be seen for teachers' mathematics expectations for the learners (Item 2); however, the patterns of mathematics expectations were somewhat different from those seen for their reading expectations. The learners with blindness $(M=3.24, \mathrm{SD}=1.02)$ and autism $(\mathrm{M}=3.02, \mathrm{SD}=1.00)$ were thought to make the most progress in their mathematics scores. The learner with spastic quadriplegia, in contrast, was expected to make the least progress $(\mathrm{M}=2.56$, $\mathrm{SD}=.89$ ) and the expectations for this learner were significantly lower than the mathematics expectations for each of the other three learners $F(3,90)=11.49, p<.01$.

In terms of learners' intellectual development (Item 3), teachers generally did not report that attending a mainstream class would be beneficial for any of the learners, as evidenced by mean scores below 3 for all of the learners. Statistically significant differences were found between expectations for learners, however, $F(3,90)=14.46, p<.01$. Teachers held the lowest expectations for the learners with spastic quadriplegia $(\mathrm{M}=2.14, \mathrm{SD}=1.25)$ and autism $(\mathrm{M}=$ $2.46, \mathrm{SD}=1.36)$. The highest expectations were for the learner with blindness $(\mathrm{M}=2.83, \mathrm{SD}=$ 1.47), and were similar to the expectations for the learner with Down syndrome $(\mathrm{M}=2.82, \mathrm{SD}=$ $1.31)$

Item 4 tapped teachers' expectations for learners' social development. It can be seen that teachers held more positive views for the social effects of a mainstream education for learners with disabilities compared to the benefits for their intellectual development, as the means for Item 4 are higher than those for Item 3 for all of the learners. Teachers reported that attending a mainstream class would most benefit the learners with blindness $(\mathrm{M}=3.35, \mathrm{SD}=1.54)$ and Down syndrome $(\mathrm{M}=3.33, \mathrm{SD}=1.44)$. The learner with autism was expected to socially benefit the least from a mainstream education $(\mathrm{M}=2.57, \mathrm{SD}=1.43)$.

Items 5, 6, and 7 on the Teachers' Attitudes and Expectations Scale examined factors related to teachers' attitudes concerning the degree of academic adjustments they would need to make to the curricula to include the learners. Item 5 asked teachers whether they would need to structure 


\section{J. Bornman \& D. K. Donohue}

their lessons differently if they had the learner in their class. Overall, the means were high (i.e., above 4) for all of the learners. Teachers reported they would need to re-structure their lessons the most to include the learner with blindness $(\mathrm{M}=4.85, \mathrm{SD}=.53)$ and this mean was significantly higher than the means of the both the learner with spastic quadriplegia $(\mathrm{M}=4.58, \mathrm{SD}=.88)$ and the learner with Down syndrome $(\mathrm{M}=4.27, \mathrm{SD}=.96)$.

Item 6 asked whether teachers felt they knew how to teach this learner. For the learners with blindness, spastic quadriplegia, and autism, the means were between 3 and 4 , indicating that teachers felt more positive than negative about their abilities to teach each of the learners. Teachers were the most confident about their abilities to teach the learner with Down syndrome $(M=4.02$, $\mathrm{SD}=1.15)$, a mean that was significantly higher than those for each of the other three learners $F(3$, $90)=9.59, p<.01$.

Item 7 asked teachers how many curricula adaptations they anticipated the learner would require. Overall, teachers anticipated they would need to make "several" to "many" adaptations (means between 3 and 4) to the curricula for all of the learners. The scores were relatively similar for each of the learners, but there was a statistically significant difference between the anticipated adaptations for the learners with Down syndrome and spastic quadriplegia $F(3,90)=4.78, p<.01$.

Items 8 and 9 relate to factors that can be provided by the school in order to help teachers implement inclusive education. Item 8 asked teachers how much extra time they would need to teach the learner. Teachers reported that they needed the least amount of time for the learner with Down syndrome $(\mathrm{M}=3.30, \mathrm{SD}=1.21)$, and this was significantly less time than they reported for each of the other learners $F(3,90)=9.74, p<.01$. They rated the learner with spastic quadriplegia as the learner who would need the most additional instructional time $(\mathrm{M}=3.87, \mathrm{SD}=1.24)$, but this score was not significantly different than the score for the learner with blindness $(\mathrm{M}=3.64$, $\mathrm{SD}=1.08)$, nor the learner with autism $(\mathrm{M}=3.64, \mathrm{SD}=1.29)$ 
Item 9 tapped teachers' attitudes about the importance of supports to teach the learner. As can be seen by the high means, teachers reported that extra supports were very important to help them teach all of the learners. The most supports were needed for the learner with blindness $(\mathrm{M}=$ $4.83, \mathrm{SD}=.46)$ and the learner with spastic quadriplegia $(\mathrm{M}=4.78, \mathrm{SD}=.59)$. The learner with Down syndrome required the fewest supports, although the mean still was high $(\mathrm{M}=4.27, \mathrm{SD}=$ 1.06) and not significantly different from the supports anticipated for the learner with autism ( $\mathrm{M}=$ $4.49, \mathrm{SD}=.95)$.

\section{MANOVA Analyses}

The factor structure of the Teachers' Attitudes and Expectations Scale was examined, with the primary purpose to identify and compute composite scores for the outcome variables for the MANOVA analyses. First, summary scores were computed across each vignette for each item (i.e., a summed total for each item combined across blindness, autism, spastic quadriplegia, Down syndrome). Then, a principal components analysis with varimax rotation was run. Two factors were determined using Kaiser's criterion of eigenvalues over 1.0. The eigenvalues revealed that the first factor explained $40.19 \%$ of the variance and the second factor explained $25.27 \%$ of the variance, for a cumulative of $65.46 \%$ variance explained. The factor loadings for the final solution can be seen in Table 4. These factors were subsequently computed into two composite scores: Factor 1 was "Expectations for the Learner", and included items 1 to 4; Factor 2 was "Teaching Adjustments", and included items 5 to 7 (6 was reverse scored when calculating composite scores). These composite scores were calculated for each of the learners and used as the dependent variables for the analyses. The results of these analyses can be found in Tables 5 and 6 . The independent variables for each of the models were age, years of education, years teaching, inclusive education training, and teaching experience with learners with disabilities. 


\section{Table 4.}

Summary of exploratory factor analysis for Teachers' Attitudes and Expectations Scale.

Principal Components Extraction with Varimax Rotation $(\mathrm{N}=93)$.

Factor Loadings

\begin{tabular}{l} 
Item \\
\hline $\begin{array}{l}\text { 1. How much progress do you think this learner will make in reading } \\
\text { skills this year? }\end{array}$
\end{tabular}

skills this year?

2. How much progress do you think this learner will make in mathematics skills this year?

3. Attending a mainstream class will help this learner's intellectual development.

4. Attending a mainstream class will help this learner's social development.

5. I would need to structure my lessons differently is I had this learner in my class.

6. I would know how to teach this learner.

7. How many adaptations to the curricula would you need to make for this learner?

Eigenvalues

$\%$ of variance

\section{Biographical Factors Influencing Teachers' Expectations for the Learner and Teaching Adjustments}

Teacher-level biographical factors that may influence teachers' attitudes toward the learner were analysed (see Table 5). Teachers' ages were found to be a positive significant predictor of their academic Expectations for the Learner for the learner with blindness $F(1,87)=4.09, p=.05$. The other significant effect was for whether or not teachers had ever taught a learner with a disability. Positive effects were evident for teachers' academic Expectations for the Learner for the learners 
with blindness $F(1,87)=8.01, p<.05$; spastic quadriplegia $F(1,87)=6.98, p<.05$; and Down syndrome $F(1,87)=4.34, p<.05$. A similar positive trend was seen for the learner with autism, but this effect did not cross the threshold of statistical significance $F(1,87)=3.20, p=.08$.

Table 5.

MANOVA for overall Expectations for Learner composite score ( $\mathrm{N}=93)$.

\begin{tabular}{|c|c|c|c|c|c|}
\hline & Item & $\mathrm{df}$ & MS & $\mathrm{F}$ & $\mathrm{p}$ \\
\hline \multirow[t]{4}{*}{ Teachers' Age } & Learner with Blindness & 1,87 & 61.85 & 4.09 & .05 \\
\hline & Learner with Autism & 1,87 & .96 & .06 & .81 \\
\hline & Learner with Spastic Quad & 1,87 & .81 & .07 & .80 \\
\hline & Learner with Down syndrome & 1,87 & 4.65 & .34 & .56 \\
\hline \multirow{4}{*}{$\begin{array}{l}\text { Years } \\
\text { education }\end{array}$} & Learner with Blindness & 1,87 & 6.25 & .41 & .52 \\
\hline & Learner with Autism & 1,87 & 8.48 & .54 & .46 \\
\hline & Learner with Spastic Quad & 1,87 & 1.54 & .13 & .73 \\
\hline & Learner with Down syndrome & 1,87 & .02 & .00 & .96 \\
\hline \multirow{4}{*}{$\begin{array}{l}\text { Years } \\
\text { teaching }\end{array}$} & Learner with Blindness & 1,87 & 25.76 & 1.71 & .20 \\
\hline & Learner with Autism & 1,87 & .03 & .00 & .97 \\
\hline & Learner with Spastic Quad & 1,87 & .33 & .03 & .87 \\
\hline & Learner with Down syndrome & 1,87 & .09 & .01 & .94 \\
\hline \multirow{4}{*}{$\begin{array}{l}\text { Inclusive } \\
\text { education } \\
\text { training }\end{array}$} & Learner with Blindness & 1,87 & 1.23 & .08 & .78 \\
\hline & Learner with Autism & 1,87 & 13.44 & .86 & .36 \\
\hline & Learner with Spastic Quad & 1,87 & 10.41 & .84 & .36 \\
\hline & Learner with Down syndrome & 1,87 & 31.21 & 2.26 & .14 \\
\hline \multirow{4}{*}{$\begin{array}{l}\text { Teaching } \\
\text { experience in } \\
\text { disability }\end{array}$} & Learner with Blindness & 1,87 & 120.94 & 8.01 & .01 \\
\hline & Learner with Autism & 1,87 & 50.03 & 3.20 & .08 \\
\hline & Learner with Spastic Quad & 1,87 & 86.30 & 6.98 & .01 \\
\hline & Learner with Down syndrome & 1,87 & 60.07 & 4.34 & .04 \\
\hline
\end{tabular}

*Note: bold font signifies $p<.05$

When examining the effects of teachers' biographical factors on their expected Teaching Adjustments (see Table 6), expected adjustments for the learner with spastic quadriplegia were influenced by teachers' age $F(1,87)=4.62, p<.05$ and inclusive education training $F(1,87)=$ 3.98, $p<.05$. Years teaching also influenced their expected adjustments for the learners with autism $F(1,87)=4.44, p<.05$ and spastic quadriplegia $F(1,87)=17.01, p<.01$. Similar positive 
trends were found for the learners with blindness $F(1,87)=3.65, p=.06$ and Down syndrome $F(1,87)=2.29, p=.14$.

Table 6.

MANOVA for overall Teaching Adjustments composite score $(\mathrm{N}=93)$.

\begin{tabular}{|c|c|c|c|c|c|}
\hline & Item & $\mathrm{df}$ & MS & $\mathrm{F}$ & $\mathrm{p}$ \\
\hline \multirow[t]{4}{*}{ Teachers' Age } & Learner with Blindness & 1,87 & .35 & .11 & .74 \\
\hline & Learner with Autism & 1,87 & 11.26 & 2.34 & .13 \\
\hline & Learner with Spastic Quad & 1,87 & 18.73 & 4.62 & .03 \\
\hline & Learner with Down syndrome & 1,87 & 3.65 & .78 & .38 \\
\hline \multirow{4}{*}{$\begin{array}{l}\text { Years } \\
\text { education }\end{array}$} & Learner with Blindness & 1,87 & .85 & .26 & .61 \\
\hline & Learner with Autism & 1,87 & .87 & .18 & .67 \\
\hline & Learner with Spastic Quad & 1,87 & .88 & .22 & .64 \\
\hline & Learner with Down syndrome & 1,87 & .70 & .15 & .70 \\
\hline \multirow{4}{*}{$\begin{array}{l}\text { Years } \\
\text { teaching }\end{array}$} & Learner with Blindness & 1,87 & 11.89 & 3.65 & .06 \\
\hline & Learner with Autism & 1,87 & 21.38 & 4.44 & .04 \\
\hline & Learner with Spastic Quad & 1,87 & 68.96 & 17.01 & .00 \\
\hline & Learner with Down syndrome & 1,87 & 10.69 & 2.29 & .14 \\
\hline \multirow{4}{*}{$\begin{array}{l}\text { Inclusive } \\
\text { education } \\
\text { training }\end{array}$} & Learner with Blindness & 1,87 & 1.96 & .60 & .44 \\
\hline & Learner with Autism & 1,87 & 1.49 & .31 & .58 \\
\hline & Learner with Spastic Quad & 1,87 & 16.15 & 3.98 & .05 \\
\hline & Learner with Down syndrome & 1,87 & 1.12 & .24 & .63 \\
\hline \multirow{4}{*}{$\begin{array}{l}\text { Teaching } \\
\text { experience in } \\
\text { disability }\end{array}$} & Learner with Blindness & 1,87 & .97 & .30 & .59 \\
\hline & Learner with Autism & 1,87 & .59 & .12 & .73 \\
\hline & Learner with Spastic Quad & 1,87 & 3.47 & .86 & .36 \\
\hline & Learner with Down syndrome & 1,87 & 1.05 & .22 & .64 \\
\hline
\end{tabular}

*Note: bold font signifies $p<.05$

\section{Supports Listed as Essential for Inclusion}

Following Item 9 on the Teachers' Attitudes and Expectations Scale, participants were asked to list any supports they thought were essential to include the learners within a mainstream class (see Table 7). In total, participants listed 14 different types of supports that they thought would facilitate the inclusion of learners with disabilities. In examining all of the supports listed across each of the learners, assistive devices, instructional materials, computers, personal 
Table 7.

Frequencies of supports teachers listed as essential to successfully include learner ( $\mathrm{N}=93$ ).

\begin{tabular}{|c|c|c|c|c|c|c|c|c|c|c|c|c|c|c|}
\hline Support & $\begin{array}{l}\text { Assitive } \\
\text { devices }\end{array}$ & $\begin{array}{c}\text { Physical } \\
\text { structur } \\
\text { al } \\
\text { assistan } \\
\text { ce }\end{array}$ & $\begin{array}{c}\text { Instructi } \\
\text { on } \\
\text { material } \\
\text { s/ IEP }\end{array}$ & $\begin{array}{c}\text { Comput } \\
\text { er } \\
\text { technolo } \\
\text { gy }\end{array}$ & $\begin{array}{l}\text { Therapy } \\
\text {, } \\
\text { therapeu } \\
\text { tic } \\
\text { material } \\
\mathrm{s}\end{array}$ & $\begin{array}{c}\text { Smaller } \\
\text { classes }\end{array}$ & $\begin{array}{l}\text { Teacher } \\
\text { 's aide, } \\
\text { personal } \\
\text { assistant }\end{array}$ & $\begin{array}{c}\text { Worksh } \\
\text { ops, } \\
\text { skill } \\
\text { training }\end{array}$ & $\begin{array}{c}\text { Parnent } \\
\text { involvm } \\
\text { ent }\end{array}$ & $\begin{array}{l}\text { Advice } \\
\text { from } \\
\text { experts }\end{array}$ & $\begin{array}{c}\text { Time to } \\
\text { complet } \\
\text { e tasks, } \\
\text { no } \\
\text { extramu } \\
\text { ral } \\
\text { activitie } \\
\text { s }\end{array}$ & $\begin{array}{l}\text { Praise, } \\
\text { recognit } \\
\text { ion }\end{array}$ & $\begin{array}{c}\text { Differen } \\
\mathrm{t} \text { salary }\end{array}$ & $\begin{array}{l}\text { Teamw } \\
\text { ork with } \\
\text { other } \\
\text { teachers }\end{array}$ \\
\hline $\begin{array}{l}\text { Learner with } \\
\text { Blindness }\end{array}$ & 55 & 4 & 35 & 15 & 8 & 6 & 23 & 21 & 6 & 2 & 15 & 2 & 8 & 0 \\
\hline $\begin{array}{l}\text { Learner with } \\
\text { Autism }\end{array}$ & 15 & 9 & 26 & 5 & 8 & 4 & 28 & 23 & 2 & 1 & 11 & 1 & 10 & 1 \\
\hline $\begin{array}{l}\text { Learner with } \\
\text { Spastic } \\
\text { quadriplegia }\end{array}$ & 24 & 18 & 23 & 15 & 8 & 3 & 44 & 20 & 1 & 3 & 6 & 1 & 7 & 2 \\
\hline $\begin{array}{l}\text { Learner with } \\
\text { Down syndrome }\end{array}$ & 13 & 1 & 27 & 9 & 8 & 2 & 25 & 19 & 4 & 1 & 4 & 4 & 8 & 0 \\
\hline
\end{tabular}


assistants/teachers' aides, and additional training were listed the most frequently as important for inclusion.

For the learner who was blind, teachers most frequently reported they would need assistive devices $(n=55)$, instructional materials $(n=35)$, personal assistant $(n=23)$, and workshops and skill training $(\mathrm{n}=21)$. The top three supports for the learner for autism were found to be a personal assistant $(n=28)$, instructional materials $(n=26)$, and additional training $(n=23)$. For the learner with spastic quadriplegia, the teachers reported that they would most often need a personal assistant $(n=44)$, assistive devices $(n=24)$, and instructional materials $(n=23)$, whereas for the learner with Down syndrome the most frequent supports noted were instructional materials $(\mathrm{n}=$ 27), a personal assistant $(n=25)$, and skills training $(n=19)$. Taken together it can be seen that there is substantial overlap between learners in the types of supports teachers reported they would require, yet there also was some differentiation in the frequencies of supports mentioned as essential between the different learners.

\section{Discussion}

The purpose of this research was to compare and contrast teachers' attitudes toward including learners with different disabilities into their mainstream classroom. Although several studies have sought to examine how teachers believed including a learner with a disability would influence them, this study specifically attempted to determine how teachers believed inclusion would influence the academic and social skills of learners with distinct impairments. In addition, the degree and types of supports that teachers thought would facilitate the inclusion of the different learners were investigated. Teachers' biographical factors also were assessed to determine whether they had an impact on the attitudes teachers held toward the hypothetical learners in the four vignettes. 
Overall, the results suggested that teachers expected relatively little reading and mathematics progress for each of the learners, as evidenced by the low means in both academic areas. They also uniformly reported that attending a mainstream class would facilitate learners' social development more than their intellectual development. These findings relate to concerns that have been expressed by other researchers (e.g., Bornman, Alant, \& Uys, 2008; Zoniou-Sideri \& Vlachou, 2006) that the focus of inclusive education for learners with disabilities is more on caring, loving, and socializing rather than learning. Low expectations, in turn, subsequently influence the goals that teachers hold for their learners and the strategies and energy that teachers utilize to help learners obtain these goals (Jordan, Glenn, \& McGhie-Richmond, 2009). The reality is that many learners with disabilities may not be academically learning because they are not being taught, or are being taught with the few free minutes that teachers have daily (Johnstone \& Chapman, 2009). Teachers of learners with disabilities need to become aware that the lack of academic progress that is evidenced by learners with disabilities may, in part, be caused by the teachers' own low expectations and goals for the learners, resulting in insufficient instruction.

Teachers expected the learner with Down syndrome to make the most progress in his reading skills, whereas the learner with blindness was expected to make the least. The low reading expectations for the learner who was blind almost surely related to the visual demands of learning to read (in the conventional way) and the teachers' lack of knowledge in Braille. This notion is supported by the frequency with which teachers listed assisted devices (e.g., Braille readers) and additional training as essential supports to teach the learner who was blind. Conversely, they held the highest mathematics expectations for the learner with blindness, suggesting that teachers were less concerned about the visual demands of teaching mathematics and could envision other methods to teach math skills to learners with blindness, perhaps through the use of teaching devices like abacuses. In contrast to the learners with blindness, spastic quadriplegia, and Down syndrome, the teachers reported the learner with autism would evidence relatively equivalent 
reading and mathematics progress indicating that teachers did not assume that the learner with autism had academic strengths in some areas but not others.

When asked about the benefits of inclusion on a learner's intellectual and social development, the learners with spastic quadriplegia and autism received the lowest scores. These results may tie into the findings of previous research that has found that teachers often hold the least favourable views of inclusion for children with multiple and severe disabilities (Scruggs \& Mastropieri, 1996) and autism (Avramidis \& Kalyva, 2007). Thus, when teachers are asked about the benefits of inclusion for learners with disabilities whose disabilities generally are more challenging for teachers to effectively manage, teachers could: (1) genuinely consider that these learners do not benefit from inclusion, or (2) may be more focused on the fact that these learners are relatively more challenging to teach and manage in the classroom context. More research will be needed in this area to disentangle exactly to what these attitudes can be attributed.

In terms of the adjustments teachers reported they would need to make, they generally reported that to include any of the learners mentioned in the vignettes, they would need to structure their lessons differently and make some adaptations to the curricula. They were significantly more confident about their abilities to teach the learner with Down syndrome compared to all of the other learners. In fact, for overall academic adjustments, teachers were most favourable toward the learner with Down syndrome on all of the items, suggesting that teachers have the fewest concerns about including learners with Down syndrome. These findings may be related to a phenomenon that has been termed the "Down syndrome advantage" (Hodapp, Ly, Fidler, \& Ricci, 2001), a commonly-held belief that, when compared to children with other disabilities, children with Down syndrome are easier to rear because they tend to be more sociable and easy-going (Hodapp, 2002). Like parents, teachers may also hold the belief about the Down syndrome advantage. On the other hand, teachers in this sample may have had more exposure to learners with Down syndrome than 
learners with other disabilities. Previous exposure may, in turn, have made teachers more confident about their abilities to include a learner with Down syndrome within their class.

The teachers also were asked to what degree school-level resources would help them facilitate inclusion. Teachers rated the learner with Down syndrome as needing significantly less additional instructional time compared to all of the other learners. When asked about the importance of supports to teach the learners, however, teachers rated this area highly (above a mean of 4) for all of the learners. When asked about what type of resources and supports would facilitate inclusion, the most frequently listed were assistive devices, instructional materials, computers, personal assistants, and extra training. A sizable proportion of the sample also reported that they would like an increased salary and no extramural activity duties.

The provision of supports appears to be a vital contributor to teachers' attitudes toward inclusion, as previous research has found that teachers' top three main concerns about including learners with disabilities into mainstream settings were: (1) inadequate support staff, (2) inadequate resources, and (3) inadequate specialist equipment at the school (Subban \& Sharma, 2006). The general lack of supports that are provided to teachers in South Africa (Nel et al., 2011) therefore is concerning and may be one important contributor to teachers developing negative attitudes toward inclusive education. If the South African Department of Education wants to make inclusion a reality, they need to provide schools and teachers with the appropriate supports to realise this policy.

The results of the MANOVA analyses suggested that teachers who had previously taught learners with disabilities had significantly more positive expectations for the academic abilities of the learners depicted in this study. Previous research (Avramidis \& Kalyva, 2007; Bornman \& Donohue, 2013; Forlin et al., 2009) has similarly found that previous exposure positively influences teachers' attitudes toward the inclusion of learners with disabilities into mainstream classrooms. These findings indicate that pre-service and additional teacher training must 
incorporate hands-on experience with children with disabilities. Training and education also should be an on-going process for teachers throughout their careers, as continuing education can keep teachers up to date about the current trends and evidence-based practices that are occurring within their field.

In terms of the adjustments teachers thought they would need to make to their curricula to include the learners in their classes, years teaching was positively related to their expected adjustments. This finding may suggest that teachers who have been teaching longer are more realistic about the workload demands of teaching learners with disabilities. Conversely, it may indicate that teachers who have been teaching for fewer years have learned more flexible teaching strategies and therefore do not expect they would need to make major adaptations to include learners with disabilities into their classes.

\section{Limitations}

There were a few limitations in this study. First, the vignettes provided to teachers included very brief descriptions of hypothetical learners with disabilities who exhibited behaviours typical of those often seen in learners with disabilities. We know that in actuality, children are complex and their behaviours are varied. The statement that any learner is "typical" can be questioned in and of itself because of the tremendous variation in behaviours, skills, and abilities that are seen in all children. We understand that teachers' attitudes are based on the "whole child", and not just a few descriptions of his disability. Yet we wanted to maintain short vignettes (because we were asking teachers to respond to four of them) and attempt to describe behaviours that are often seen in learners with specific disabilities in order to get an idea of how teachers generally feel about learners who generally present with this disability.

We also acknowledge that this research is more aligned with the medical model (i.e., focus on the child's disability) rather than the social model (i.e., focus on environmental barriers) of disability. Although it is changing and the Education White Paper 6 (South African Department of 


\section{J. Bornman \& D. K. Donohue}

Education, 2001) advocates the social model of disability, the South African schooling system still is very much aligned with the medical model of disability and to determine teachers' attitudes toward inclusion it is more straightforward to present teachers with categories of disability rather than a list of environmental barriers to learning. Future research of this type in South Africa may be able to focus more on environmental barriers to learning rather than on children's disabilities.

Another limitation is that teachers were sampled either from special schools in South Africa, or were enrolled in a university course to obtain an advanced certificate in the education of learners with disabilities; therefore all participants had at least some familiarity with issues surrounding inclusion and the education of learners with disabilities. Moreover, teachers from only three provinces in South Africa were sampled, most predominantly teachers from the Gauteng province, which is the richest and most resourced province within South Africa. This sampling may have biased the results as teachers in other, less resourced provinces may have different attitudes regarding inclusive education. Therefore, the results of this study should not be viewed as fully representative of all South African teachers because there may be attitudinal distinctions among teachers who were not sampled.

Albeit slowly, progress toward inclusive policy is being made in South Africa. Future research may want to track changes in teachers' attitudes over time to determine whether teachers' attitudes remain static or alter-either in a positive or negative direction — as inclusive policies progressively become implemented across South Africa. These future studies could indicate whether teachers who previously held negative attitudes toward inclusion shifted to more positive attitudes as they gained exposure and experience with learners with disabilities. Conversely, teachers' attitudes may become more negative if they find themselves in a position with no supports or services to help them implement policies. Thus, only time will tell how well teachers receive and work to realize inclusive education policy in South Africa. 


\section{Conclusion}

With the publication of the Education White Paper 6 (South African Department of Education, 2001), South African teachers increasingly have become familiar with inclusive education policies and increasing expectations for them to educate a diverse body of learners within the same classroom. Yet, teachers understandably still hold many reservations and ambivalence about inclusion: on the one hand they strongly support the ideals of human rights for children with disabilities. At the same time, they see realistic concerns and the impracticalities of including learners with disabilities when some have yet to acquire the skills to teach such learners, and schools overwhelming lack the services needed to support teachers in their endeavours. Inclusive policy remains an important goal for which educators should aim, however, as all South African learners ultimately will benefit from early exposure to diversity.

\section{References}

Avramidis, E., Bayliss, P., \& Burden, R. (2000). A survey into mainstream teachers' attitudes towards the inclusion of children with special educational needs in the ordinary school in one local educational authority, Educational Psychology, 20, 191-211. doi: 10.1080/713663717

Avramidis, E., \& Kalyva, E. (2007). The influence of teaching experience and professional development on Greek teachers' attitudes towards inclusion. European Journal of Special Needs Education, 22, 367-389.

Avramidis, E., \& Norwich, B. (2002). Teachers' attitudes towards integration/inclusion: A review of the literature. European Journal of Special Needs Education, 17, 129-147.

Bornman, J., Alant, E., \& Uys, C. J. E. (2008). From caring to education for children with severe disabilities in a rural context. In A. T. Waddell, \& R. M. McBride (Eds.), New research on early childhood education (pp. 139-167). New York: Nova Publishers. 
Bornman, J., \& Donohue, D. K. (2013). South African teachers' attitudes toward learners with barriers to learning: ADHD and LNFS. International Journal of Disability, Development, \& Education, 60, 85-104. doi: 10.1080/1034912X.2013.786554

Chhabra, S., Srivastava, R., \& Srivastava, I. (2010). Inclusive education in Botswana: The perceptions of school teachers. Journal of Disability Policy Studies, 20, 219-228.

Eloff, I., Swart, E., \& Engelbrecht, P. (2002). Including learners with physical disabilities: Stressful for teachers? Koers, 67, 77-99.

Engelbrecht, P. (2006). The implementation of inclusive education in South Africa after ten years of democracy. European Journal of Psychology, 21, 253-264.

Engelbrecht, P., Oswald, M., \& Forlin, C. (2006). Promoting the implementation of inclusive eduation in primary schools in South Africa. British Journal of Special Education. 33, 121129.

Engelbrecht, P., M. Oswald, E. Swart, \& Eloff, I. (2003). Including learners with intellectual disabilities; stressful for teachers? International Journal of Disability, Development and Education, 50(3), 293-308.

Forlin, C., Loreman, T., Sharma, U., \& Earle, C. (2009). Demographic differences in changing pre-service teachers' attitudes, sentiments, and concerns about inclusive education. International Journal of Inclusive Education, 13, 195-209.

Hay, J. F., Smit, J., \& Paulsen, M. (2001). Teacher preparedness for inclusive education. South African Journal of Education, 21, 213-218.

Hodapp, R. M. (2002). Parenting children with mental retardation. In M. H. Bornstein (Ed.), Handbook of Parenting: Vol. 1: Children and parenting (2nd ed., pp. 355-381). Mahwah, NJ: Lawrence Erlbaum Associates, Inc

Hodapp, R. M., Ly, T. M., Fidler, D. J., \& Ricci, L. A. (2001). Less stress, more rewarding: Parenting children with Down syndrome. Parenting: Science and Practice, 1, 317-337. 
Johnstone, C. J., \&. Chapman, D. W. (2009). Contributions and constraints to the implementation of inclusive education in Lesotho. International Journal of Disability, Development, and Education, 56, 131-148. doi: 10.1080/10349120902868582

Jordan, A., Glenn, C., \& McGhie-Richmond, D. (2009). The supporting effective teaching (SET) project: The relationship of inclusive teaching practices to teachers' beliefs about disability and ability, and about their roles as teachers. Teaching and Teacher Education, 20, 259-266.

Lawshe, C. H. (1975). A quantitative approach to content validity. Personnel Psychology, 28, $563-$ 575.

Lindqvist, G., \& Nilholm, C. (2013). Making schools inclusive? Educational leaders' view on how to work with children in need of special support. International Journal of Inclusive Education, 17, 95-110. doi:10.1080/13603116.2011.580466

Lomofsky, L., \& Lazarus, C. (2001). South Africa: First steps in the development of an inclusive education system. Cambridge Journal of Education, 31, 303-320.

Nel, N., Muller, H., \& Rheeders, E. (2011). Support services within inclusive education in Gauteng: The necessity and efficiency of support. Mevlana International Journal of Education, 1, 38-53.

Oswald, M. (2007). Training teachers to become inclusive professionals. In P. Engelbrecht, \& L. Green (Eds.), Responding to the challenges of inclusive education in southern Africa (pp. 140-158). Pretoria, South Africa: Van Schaik Publishers.

Pecek, M., Cuk, I., \& Lesar, I. (2008). Teachers' perceptions of the inclusion of marginalized groups. Educational Studies, 34, 225-239.

Scruggs, T. E., \& Mastropieri, M. A. (1996). Teacher perceptions of mainstreaming inclusion, 1958-1995: a research synthesis, Exceptional Children, 63, 59-74. 
South African National Department of Education. (2001). Education White Paper 6. Special needs education: building an inclusive education and training system. Pretoria, South Africa: National Department of Education.

Subban, P., \& Sharma, U. (2006). Primary school teachers' perceptions of inclusive education in Victoria, Australia. International Journal of Special Education, 21, 42-52.

United Nations Educational, Scientific and Cultural Organization. (UNESCO). (1994). Salamanca Statement and Framework for Action on special needs education. New York: Author.

Zoniou-Sideri, A., \& Vlachou, A. (2006). Greek teachers' belief systems about disability and inclusive education. International Journal of Inclusive Education, 10, 379-394. 